\title{
Characterization and Permeation of Microfabricated Palladium Membrane
}

\author{
Yi Zhang ${ }^{1}$, Jian Lu ${ }^{1}$, Tsuyoshi Ikehara ${ }^{1}$, Ryutaro Maeda ${ }^{1}$ and Chikashi Nishimura ${ }^{2}$ \\ ${ }^{1}$ Advanced Manufacturing Research Institute, National Institute of Advanced Industrial Science and Technology (AIST), \\ Tsukuba 305-8564, Japan \\ ${ }^{2}$ Ecomaterials Center, National Institute for Materials Science, Tsukuba 305-0047, Japan
}

\begin{abstract}
Single-layer Pd membrane with the thickness of about $2.5 \mu \mathrm{m}$ was successfully prepared by microfabrication technology. Hydrogen permeation of the as-prepared Pd membrane was investigated in the temperature range of 473-673 K under hydrogen transmembrane pressure of $\sim 40 \mathrm{kPa}$. Hydrogen permeation of Pd membrane with the thickness of $0.70 \mathrm{~mm}$ was also carried out for comparisons. It was found that the hydrogen permeability of the $2.5 \mu \mathrm{m}$-thick Pd membrane was about half of that of the $0.7 \mathrm{~mm}$-thick Pd membrane. Surface resistance was less significant in hydrogen permeation through the thin microfabricated Pd membrane than thin Pd membranes supported by porous materials. Grain growth was observed in the thin microfabricated Pd membrane upon hydrogen permeation.
\end{abstract}

(Received October 21, 2005; Accepted December 19, 2005; Published February 15, 2006)

Keywords: palladium, membrane, hydrogen permeation

\section{Introduction}

Hydrogen permeation of thin Pd membranes has been an interesting topic for many years because Pd and Pd-based membranes have unmatched potential to be used as hydrogen separation membranes in many applications. ${ }^{1)}$ There are numerous literatures on hydrogen permeation of thin $\mathrm{Pd}$ membrane. ${ }^{2,3)}$ Porous materials including ceramic and metal are used to mechanically support the thin Pd membrane in most literatures. ${ }^{4-7)}$ Using the porous support, it is easy to prepare the thin Pd membrane with the thickness from several hundred nanometers to several microns. The thin $\mathrm{Pd}$ membranes have been successfully prepared on different porous support materials by physical and chemical deposition methods such as sputtering, CVD and electroless plating. However, it is difficult to get thin Pd membranes without pinhole and other defects. ${ }^{8,9)}$ As a result, it is difficult to obtain complete hydrogen selectivity for the thin $\mathrm{Pd}$ membrane supported by porous materials. The pinholes mainly result from the rough surface of porous materials. Many efforts have been made to reduce the surface roughness of porous materials. ${ }^{10)}$ In addition, porous supports have resistance on hydrogen mass transfer. The resistance became significant when Pd membrane was several micrometers thick so that it is difficult to know hydrogen permeability of thin Pd membrane. Instead, hydrogen permeance of $\mathrm{Pd}$ coated composite membrane could be only available. The hydrogen permeance is determined not only by the thin $\mathrm{Pd}$ membrane but also the porous materials. The pore size and porosity of the support determine resistance to hydrogen mass transfer. Therefore, there is a large discrepancy among measured permeabilities of the thin Pd membranes from different literatures because of different porous materials as support. It is, however, necessary to know intrinsic hydrogen permeation of the thin Pd membrane for many applications, particularly for micro membrane reactor technology, which becomes more and more attractive for portable applications. ${ }^{11,12)}$ Such knowledge is also helpful for us to further understand the hydrogen permeation of the $\mathrm{Pd}$-coated porous composite membranes.

In this work, a $2.5 \mu \mathrm{m}$-thick Pd membrane was prepared using microfabrication technology. The thin Pd membrane was supported by Ni metal with channel structure so that there would be no resistance to hydrogen mass transfer during its hydrogen permeation. Therefore, it was possible to know the intrinsic hydrogen permeation characteristics of the thin Pd membrane. In addition, the excellent mechanical properties of $\mathrm{Ni}$ metal made it possible to use conventional gas permeation method for characterization of the thin $\mathrm{Pd}$ membrane so that the results of this work could be compared with literature results.

\section{Experimental}

Figure 1 shows the fabrication procedure of thin $\mathrm{Pd}$ membrane. A $2.5 \mu \mathrm{m}$-thick Pd membrane was prepared using d.c. sputtering method. A $99.99 \%$ pure Pd target was used. The thin Pd membrane was supported by a $50 \mu$ m-thick Ni layer with channel structure. Nickel metal was chose because it has excellent mechanical properties and much lower permeability than Pd metal. ${ }^{13)}$ Hydrogen permeation through the Ni layer could be negligible relative to that through the thin Pd membrane. It could be draw the conclusion that hydrogen could only permeate through the thin Pd membrane, as shown in Fig. 1(h). In essential, the thin Pd membrane supported by $\mathrm{Ni}$ metal could be regarded as single-layer Pd membrane during hydrogen permeation. A $0.7 \mathrm{~mm}$-thick Pd membrane was also prepared from commercially sheet for comparisons.

Hydrogen permeation was carried out in a conventional gas permeation apparatus using pure hydrogen. ${ }^{14)}$ Aluminum gaskets were used for gas-tightness. The permeation temperature range was 473-673 K. Membrane sample was loaded into the permeation system and annealed in vacuum at $673 \mathrm{~K}$ for $30 \mathrm{~min}$. After the gas-tightness and leakage evaluation, both the upstream and downstream side of the permeation system were opened to air for $5 \mathrm{~min}$ as baking treatment to remove the contaminations on the thin Pd membrane. The hydrogen permeation experiments were carried out in the temperature range of 473-673 K. The downstream side was kept in continuous evacuation so the downstream pressure could be regarded as zero. The maximum upstream pressure of hydrogen was $40 \mathrm{kPa}$. The effective permeation area of the as-prepared Pd membrane was investigated under SEM. It 

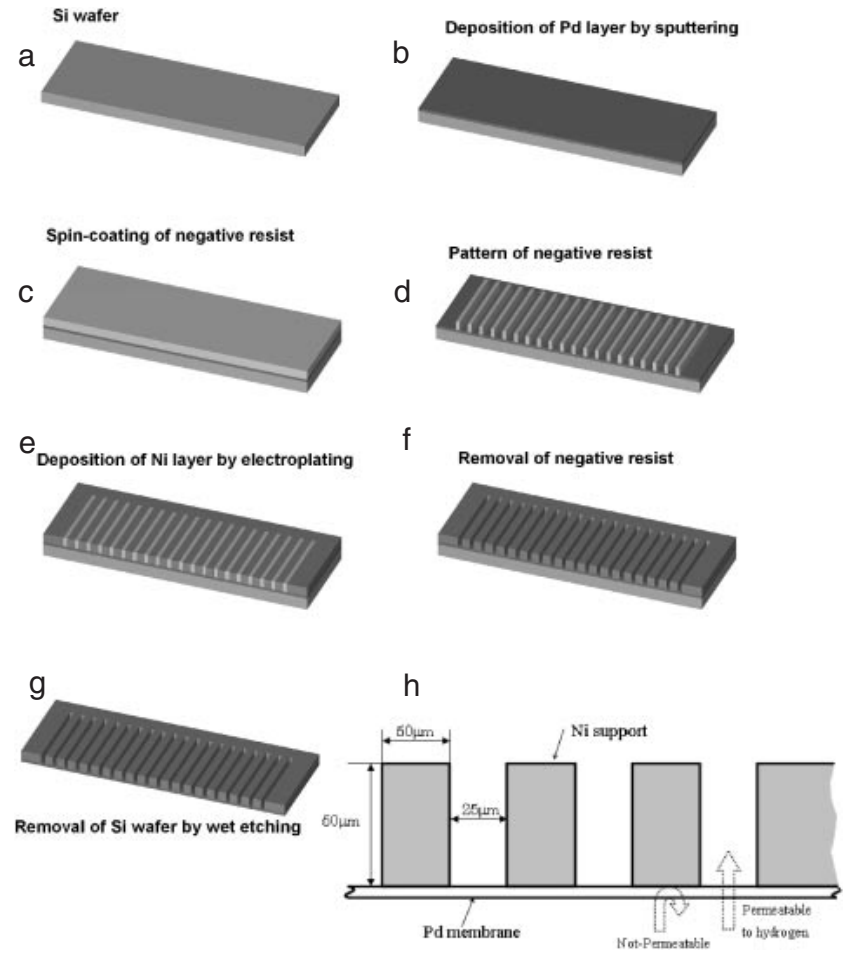

Fig. 1 Schematic of microfabrication sequences (a-g) and channel structure (h).

was about $5.54 \mathrm{~mm}^{2}$. The hydrogen permeability of the thin Pd membrane was measured using the following equation:

$$
\Phi=\frac{F \times L}{A \times\left(P_{\mathrm{U}}^{0.5}-P_{\mathrm{D}}^{0.5}\right)},
$$

where $\Phi, F, L, A, P_{\mathrm{U}}$ and $P_{\mathrm{D}}$ denote permeability, permeation flow, membrane thickness, upstream pressure and downstream pressure. Since the downstream side was kept in vacuum in this work, the eq. (1) could be rewritten as follows:

$$
\Phi=\frac{F \times L}{A \times P_{\mathrm{U}}^{0.5}}
$$

\section{Samples were examined by XRD and SEM.}

\section{Results and Discussion}

Figure 2 shows XRD patterns of the thin Pd membrane asprepared and after permeation experiments. The thin $\mathrm{Pd}$ membrane was polycrystalline with $\left(\begin{array}{lll}1 & 1 & 1\end{array}\right)$ orientation. There was no noticeable difference between XRD patterns of the thin Pd membrane before and after permeation experiments except that the (lllll) peak shifted to the higher angle owing to the annealing effect during the permeation.

Figure 3 is SEM morphology of as-prepared Pd membrane. The Pd membrane was dense and pinhole-free. Figure 4 shows cross-sectional images of the thin $\mathrm{Pd}$ membrane with Ni support. The thickness of Pd membrane was about $2.5 \mu \mathrm{m}$ [as seen in Fig. 4(a)]. There was deformation in the Pd membrane in Fig. 4(b), which mainly resulted from the residual stress of the Pd membrane formed during the microfabrication procedure. It was found that the thin $\mathrm{Pd}$ membrane had excellent mechanical performance during the preparation of cross-sectional sample. We could draw the conclusion that single-layer thin Pd membrane was successfully prepared by the microfabrication procedure demonstrated in Fig. 1.

Figure 5 shows SEM images of the thin Pd membrane after hydrogen permeation experiments at the temperature range of 473-673 K. It could be seen that grain size was different at the upstream and downstream side of the thin Pd membrane after permeation experiments. The grain sizes of the $\mathrm{Pd}$ membrane at the upstream side were in the range of $0.2-$ $1.5 \mu \mathrm{m}$, while those at the downstream side were in the range of $0.5-5 \mu \mathrm{m}$. This was consistent with our previous work in which it was shown that the grains of Pd film at the downstream side were bigger than those at upstream side upon permeation; ${ }^{15,16)}$ the grain growth had occurred during permeation. From different grain sizes at upstream and downstream side, it could be inferred that grain growth had occurred during the hydrogen permeation in this work. The biggest grains of the thin Pd membrane were seven or even ten times larger than the smallest ones, suggesting that secondary grain growth had occurred. It was possible to suppress the grain growth of the Pd membrane through the addition of silver element to Pd metal. ${ }^{15)}$ It is unclear whether the grain growth was benefit or not to hydrogen permeability of metals. ${ }^{17,18)}$ It was found that hydrogen permeation in Pd$\mathrm{Ag}$ alloy membrane was improved when the $\mathrm{Pd}-\mathrm{Ag}$ grain size increased from about 20 to $60 \mathrm{~nm},{ }^{17)}$ while hydrogen permeation in nanocrystalline $\mathrm{Ni}$ with the grain size of about $100 \mathrm{~nm}$ was remarkably larger in comparison with microcrystalline $\mathrm{Ni}$ with the grain size of about $2 \mu \mathrm{m}$.

Figure 6 is Arrhenius plot of temperature dependence of hydrogen permeability of the thin and thick Pd membrane prepared in this work. The hydrogen permeability of the $0.7 \mathrm{~mm}$-thick Pd membrane was slightly higher than the literature results. ${ }^{19)}$ The hydrogen permeability of the $2.5 \mu \mathrm{m}$ thick Pd membrane was lower than that of the $0.7 \mathrm{~mm}$-thick $\mathrm{Pd}$ membrane. It was about $50-60 \%$ of the latter. For example, hydrogen permeability of the $2.5 \mu \mathrm{m}$-thick $\mathrm{Pd}$ membrane was $6.98 \times 10^{-9} \mathrm{~mol} \mathrm{H}_{2} \mathrm{~m}^{-1} \mathrm{~s}^{-1} \mathrm{~Pa}^{-0.5}$ at $673 \mathrm{~K}$, while that of the $0.7 \mathrm{~mm}$-thick $\mathrm{Pd}$ membrane was about $1.32 \times 10^{-8} \mathrm{~mol} \mathrm{H}_{2} \mathrm{~m}^{-1} \mathrm{~s}^{-1} \mathrm{~Pa}^{-0.5}$. Hydrogen permeation through dense solids could be described by the following equation,

$$
J=\frac{\Phi \times\left(P_{\mathrm{U}}^{n}-P_{\mathrm{D}}^{n}\right)}{L},
$$

where $J, P_{\mathrm{U}}, P_{\mathrm{D}}$ and $n$ are permeation flux, upstream pressure, downstream pressure and pressure exponent. Since the downstream side was kept in vacuum during the permeation, the eq. (3) was rewritten as follows:

$$
J=\frac{\Phi \times P_{\mathrm{U}}^{n}}{L}
$$

If the hydrogen permeation was bulk-diffusion limited, the pressure exponent was 0.5 . If the hydrogen permeation was surface-reaction limited, the pressure exponent was 1. Table 1 lists the pressure exponent of hydrogen permeation of the thin Pd membrane prepared in this work. The pressure exponent was calculated from the pressure dependence of hydrogen permeation flux through the $2.5 \mu \mathrm{m}$-thick $\mathrm{Pd}$ 


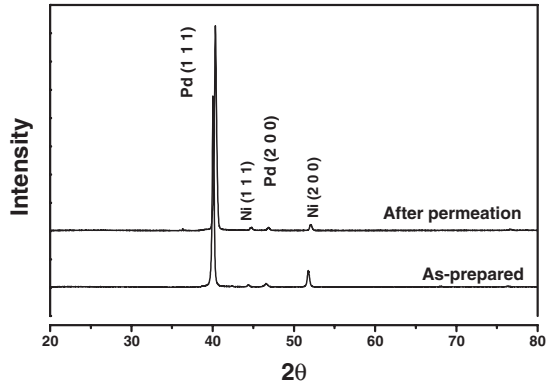

Fig. 2 XRD patterns of thin Pd membrane as prepared and after permeation.
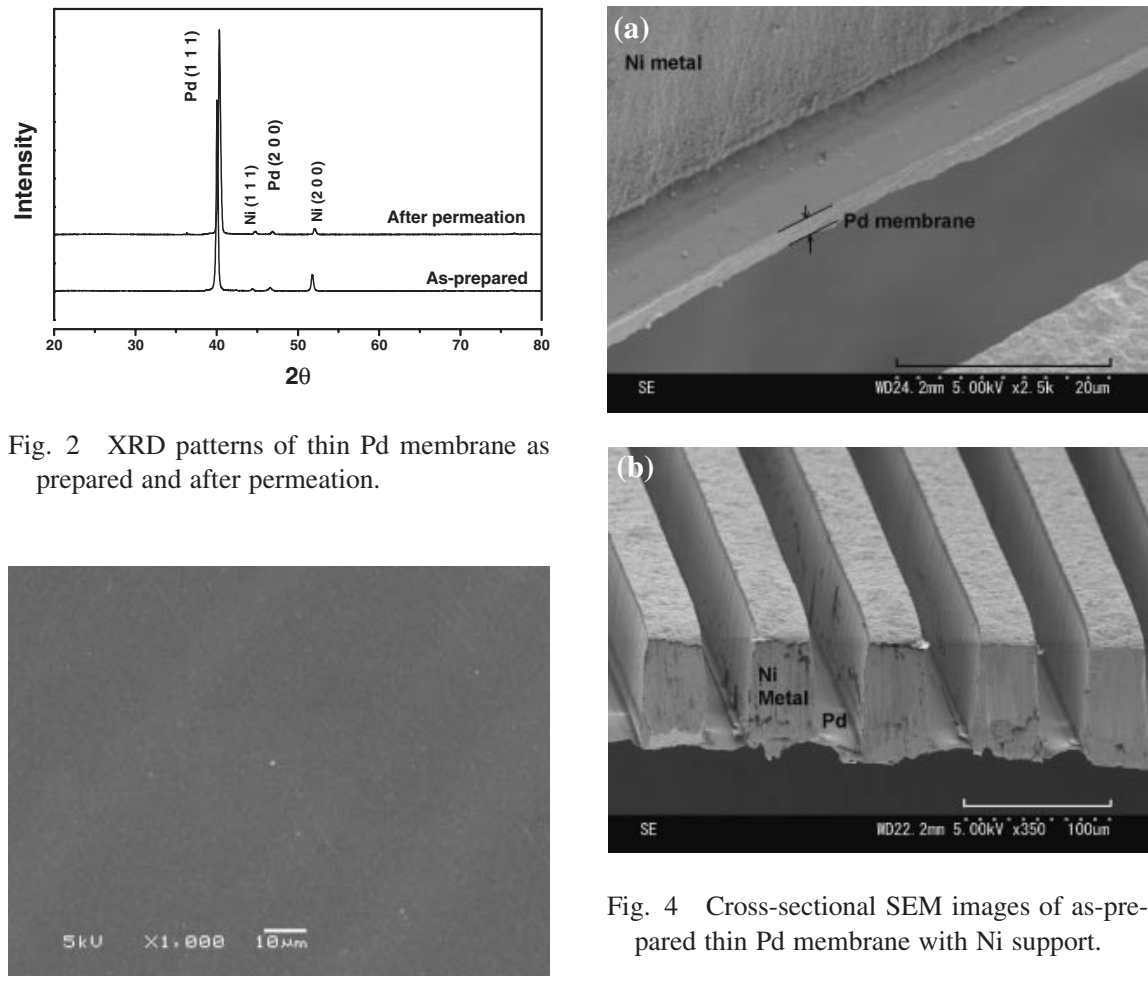

Fig. 4 Cross-sectional SEM images of as-prepared thin Pd membrane with Ni support.
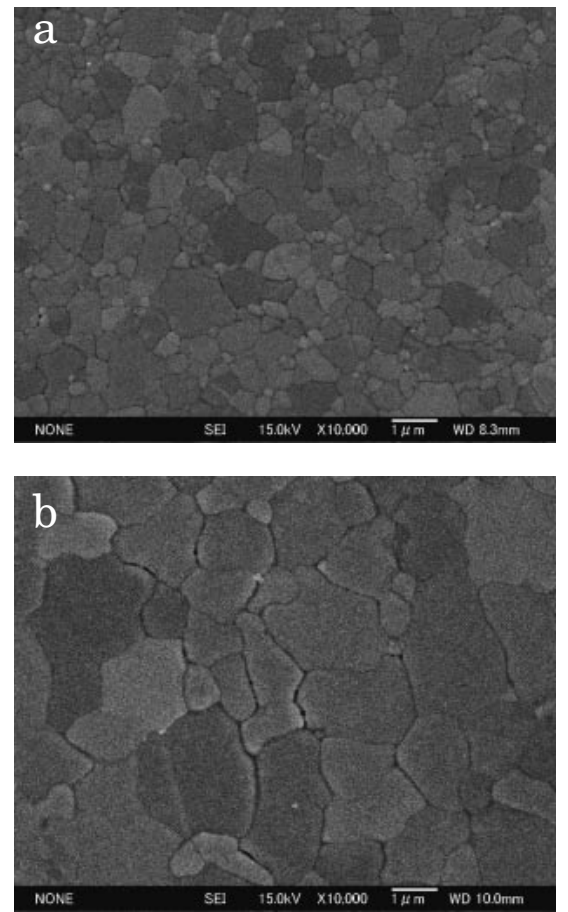

Fig. 5 SEM images of the thin Pd membrane after permeation. (a) Downstream side; (b) Upstream side.
Fig. 3 Surface morphology of as-prepared thin Pd membrane.

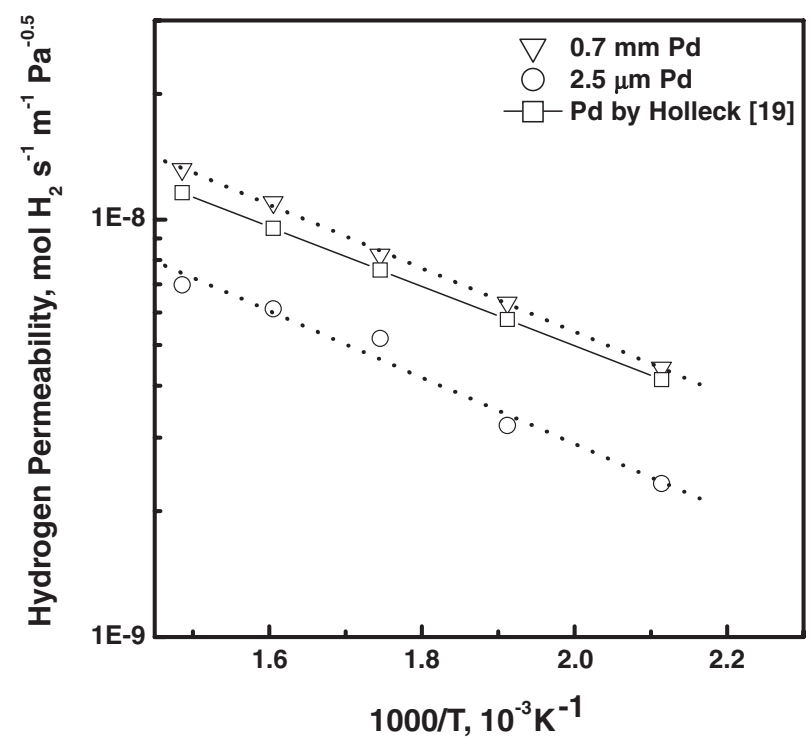

Fig. 6 Arrhenius plot of temperature dependence of hydrogen permeability of Pd membranes.

membrane. The exponent decreased from 0.86 to 0.73 with increasing temperature, suggesting that surface resistance was significant at low permeation temperature and became less with increasing the temperature. As a result, the temperature dependence of hydrogen permeability of the $2.5 \mu \mathrm{m}$-thick Pd membrane had no linearity as well as that for the $0.7 \mathrm{~mm}$-thick Pd membrane.

In Fig. 7, the present results are compared with the hydrogen permeabilities of thin Pd membranes with the thickness below $10 \mu \mathrm{m}$ in the literature. The numbers in the figure are the thickness of Pd membrane. To our knowledge,
Table 1 Pressure exponents of hydrogen permeation of Pd membranes from this work and literatures.

\begin{tabular}{lccc}
\hline Authors & $\begin{array}{c}\text { Thickness } \\
(\mu \mathrm{m})\end{array}$ & $\begin{array}{c}\text { Temperature } \\
(\mathrm{K})\end{array}$ & $\begin{array}{c}\text { Pressure } \\
\text { exponent }\end{array}$ \\
\hline & & 673 & 0.73 \\
This work & 2.5 & 623 & 0.74 \\
& & 573 & 0.77 \\
& & 523 & 0.84 \\
& 1 & $2973-773$ & 0.86 \\
\hline Yan $^{29)}$ & 3 & $573-873$ & 1 \\
\hline Kusakabe & & & \\
\hline
\end{tabular}

the thin Pd membrane prepared in this work had the highest permeability. There was great discrepancy among measured hydrogen permeabilities in the literature. The difference between the highest and the lowest values was three order and more. The hydrogen permeance of $4-\mu \mathrm{m}$ thick $\mathrm{Pd}$ membrane measured by Souleimanova et al. was $6.76 \times$ $10^{-10} \mathrm{~mol} \mathrm{H}_{2} \mathrm{~m}^{-1} \mathrm{~s}^{-1} \mathrm{~Pa}^{-0.5}$ at $\left.673 \mathrm{~K}^{25}\right)$ The hydrogen permeance of $2-\mu \mathrm{m}$ thick $\mathrm{Pd}$ membrane measured by Shu et al. was about $4 \times 10^{-9} \mathrm{~mol} \mathrm{H}_{2} \mathrm{~m}^{-1} \mathrm{~s}^{-1} \mathrm{~Pa}^{-0.5}$ at $673 \mathrm{~K}^{5)}$ The hydrogen permeance of $3-\mu \mathrm{m}$ thick Pd membrane measured by Kusakabe et al. was only $2.1 \times 10^{-12} \mathrm{~mol} \mathrm{H}_{2} \mathrm{~m}^{-1} \mathrm{~s}^{-1}$ $\mathrm{Pa}^{-0.5}$ at $673 \mathrm{~K}^{22)}$ Except for the thin $\mathrm{Pd}$ membrane prepared in this work, the other thin Pd membranes were supported by porous materials. Table 1 summarizes the pressure exponent obtained in the present work comparing with those in the literature. There was no temperature dependence for pressure exponent of hydrogen permeation through thin Pd membranes supported by porous materials; ${ }^{22,25)}$ the exponent was 1 in temperature range of $295-873 \mathrm{~K}$. Therefore, hydrogen permeation of thin $\mathrm{Pd}$ membrane on porous materials was 


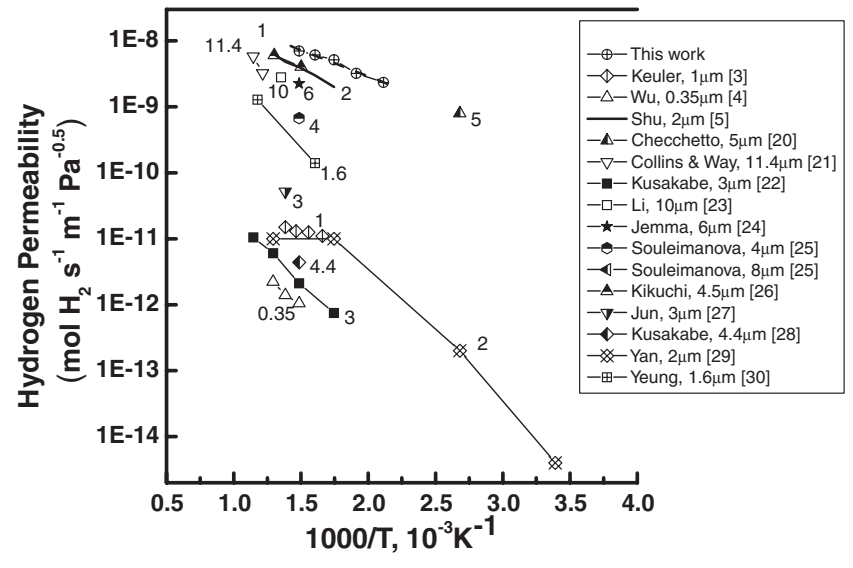

Fig. 7 Hydrogen permeability of thin Pd membranes from this work and literatures.

mainly surface-reaction limited in the temperature range of $\sim 873 \mathrm{~K}$. However, a model recently developed by Tao and Ward suggested that if there is no external mass transfer resistance, hydrogen permeation of clean $\mathrm{Pd}$ is mainly bulkdiffusion limited for temperatures higher than $573 \mathrm{~K}$ and membrane thickness approximate $1 \mu \mathrm{m} .{ }^{31)}$ This is supported by the results of this work. The pressure exponent was about 0.77 at $573 \mathrm{~K}$, suggesting that the hydrogen permeation through the thin Pd membrane prepared by microfabrication method was not completely surface-reaction limited. The surface resistance reduced with increasing temperature. It indicated that the resistance of porous materials was so significant that it was difficult to know intrinsic hydrogen permeation behavior of Pd materials when membrane thickness was less than $10 \mu \mathrm{m}$.

\section{Conclusions}

Single-layer dense Pd membrane with the thickness of about $2.5 \mu \mathrm{m}$ was successfully prepared using microfabrication technology. The pressure exponent of hydrogen permeation through the thin Pd membrane decreased from 0.86 to 0.73 when the permeation temperature increased from 473 to $673 \mathrm{~K}$, suggesting that surface resistance becomes less significant with the increasing temperature. This work showed that it is possible to prepare single-layer thin metallic membrane using microfabrication technology for hydrogen permeation investigation.

\section{REFERENCES}

1) S. N. Paglieri and J. D. Way: Sep. Purif. Meth. 31 (2002) 1-169.

2) M. Amano, C. Nishimura and M. Komaki: Mater. Trans., JIM 31 (1990) 404-408.

3) J. N. Keuler, L. Lorenzen and S. Miachon: Sep. Sci. Tech. 37 (2002) 379-401.

4) L. Q. Wu, N. Xu and J. Shi: Ind. Eng. Chem. Re. 39 (2000) 342-348.

5) J. Shu, BPA Grandjean, S. Kaliaguine, A. GiroirFendler and JA Dalmon: J. Chem. Soc.-Faraday Trans. 92 (1996) 2745-2751.

6) S. Uemiya, N. Sato, H. Ando, Y. Kude, T. Matsuda and K. Kikuchi: J. Membr. Sci. 56 (1991) 303-313.

7) A. W. Li, W. Q. Liang and R. Hughes: Thin Solid Films 350 (1999) $106-112$.

8) S. Tosti, L. Bettinali and V. Violante: Int. J. Hydrogen Energy 25 (2000) 319-325

9) S. Tosti, L. Bettinali, S. Castelli, F. Sarto, S. Scaglione and V. Violante: J. Membr. Sci. 196 (2002) 241-249.

10) A. W. Li, W. Q. Liang and R. Hughes: Sep. Purifi. Tech. 15 (1999) 113-119.

11) S. V. Karnik, M. K. Hatalis and M. V. Kothare: J. Microelectromechan. Sys. 12 (2003) 93-100.

12) A. V. Pattekar and M. V. Kothare: J. Microelectromechan. Sys. 13 (2004) 7-18.

13) W. M. Robertson: Zeitschrift fur Metallkunde 64 (1973) 436-443.

14) M. Amano, M. Komaki and C. Nishimura: J. Less-Common Met. 172 (1991) 727.

15) Y. Zhang, M. Komaki and C. Nishimura: J. Membr. Sci. 246 (2005) $173-180$.

16) Y. Zhang, R. Maeda, M. Komaki and C. Nishimura: J. Membr. Sci. 269 (2006) 60-65.

17) B. A. McCool and Y. S. Lin: J. Mater. Sci. 36 (1999) 3221-3227.

18) D. R. Arantes, X. Y. Huang and R. Kirchheim: Acta Metall. Mater. 41 (1993) 3215-3222.

19) G. L. Holleck: J. Phys. Chem. 74 (1970) 503-511.

20) R. Checchetto, N. Bazzanella, B. Patton and A. Miotello: Surf. Coat. Technol. 177-178 (2004) 73-79.

21) J. P. Collins and J. D. Way: Ind. Eng. Chem. Res. 32 (1993) 30063013.

22) K. Kusakabe, M. Takahashi, H. Maeda and S. Morooka: J. Chem. Eng. Jpn. 34 (2001) 703-705.

23) A. Li, W. Liang and R. Hughes: Catal. Today 56 (2000) 45-51.

24) N. Jemaa, J. Shu, S. Kaliaguine and B. Grandjean: Ind. Eng. Chem. Res. 35 (1996) 973-977.

25) R. S. Souleimanova, A. S. Mukastan and A. Varma: AIChE J. 48 (2002) 262-268.

26) E. Kikuchi: Catal. Today 25 (1995) 333-337.

27) C. S. Jun and K. H. Lee: J. Membr. Sci. 157 (1999) 107-115.

28) K. Kusakabe, S. Yokoyama, S. Morooka, J. Hayashi and H. Nagata: Chem. Eng. Sci. 51 (1996) 3027-3032.

29) S. Yan, H. Maeda, K. Kusakabe and S. Morooka: Ind. Eng. Chem. Res. 33 (1994) 616-622.

30) K. Yeung, S. Christiansen and A. Varma: J. Membr. Sci. 159 (1999) $107-122$.

31) T. L. Ward and T. Dao: J. Membr. Sci. 153 (1999) 211-231. 